Norio Sakuragawa - Shin Enosawa - Takashi Ishii

Ramasamy Thangavel $\cdot$ Toshiko Tashiro

Torayuki Okuyama · Seiichi Suzuki

\title{
Human amniotic epithelial cells are promising transgene carriers for allogeneic cell transplantation into liver
}

\begin{abstract}
As human amniotic epithelial tissue is formed on about the eighth day after fertilization, human amniotic epithelial cells (hAEC) may have multipotency to differentiate into various organs, such as brain, heart, or liver. In this study, we showed evidence of the synthesis and excretion of albumin by hAEC, by immunostaining and enzymelinked immunoassay. Reverse transcription-polymerase chain reaction (RT-PCR) and western blot analyses revealed the expression of albumin mRNA and protein, respectively. In addition, hAEC also demonstrated immunoreactivity to genetic markers of liver lineage, such as human serum albumin and $\alpha$-fetoprotein. Transplanted hAEC to Scid mouse liver showed positive immunoreactivity to albumin and $\alpha$-fetoprotein. Genetically modified cells containing the $\beta$-galactosidase ( $L a c Z$ ) gene (AxCALacZ) were integrated in liver parenchyma. Human polymorphic gene analysis in Scid mouse liver after the implantation of hAEC showed that these Scid mouse livers obviously contained this human-specific gene until day 7 after the cell transplantation. As hAEC do not cause any acute rejection by allotransplantation, we conclude that hAEC may be useful as a transgene carrier to treat patients with inherited liver diseases.
\end{abstract}

Key words Human amniotic epithelial cells - Cell transplantation $\cdot$ Albumin $\cdot$ Gene therapy $\cdot$ Liver stem cells

N. Sakuragawa $(\bowtie) \cdot S$. Enosawa $\cdot$ T. Ishii $\cdot$ R. Thangavel

T. Tashiro $\cdot$ T. Okuyama

Department of Inherited Metabolic Disease, National Institute of

Neuroscience, NCNP, 4-1-1, Ogawahigashi, Kodaira, Tokyo 187-

8502, Japan

Tel. +81-42-346-1716; Fax +81-42-346-1746

e-mail: sakuraga@ncnp.go.jp

S. Enosawa $\cdot$ T. Okuyama $\cdot$ S. Suzuki

Department of Experimental Surgery and Bioengineering, National

Children's Medical Research Center, Tokyo, Japan

\section{Introduction}

Liver cell transplantation has been advocated for gene therapy or acute liver support (Sigal et al. 1992). The survival and function of the transplanted hepatocytes has been demonstrated in mutant rats lacking bilirubin-uridine diphosphate glucuronosyltransferase activity (Gunn rat) and rats with inherited lack of plasma albumin (Nagase analbuminemia rat) (Demetrious et al. 1986; Gupta et al. 1991). The concept of a liver stem cell has been confirmed by studies on embryogenesis of the liver, on experimental carcinogenesis, and on the properties of non-hepatocytic epithelial cells (Grisham and Thorgeirsson 1997). The availability of these hepatic stem cells may accelerate the development of clinical liver cell transplantation.

On about the eighth day after fertilization, human amniotic epithelial cells (hAEC) are formed from amnioblasts, which are adjacent to cytotrophoblasts and line the amniotic cavity together with the rest of the epiblast. Accordingly, hAEC may have the potentiality to differentiate into various organs, such as the brain, heart, or liver. Immunologically, hAEC are naïve because they lack the expression of MHC class II and mildly express MHC class I (Sakuragawa et al. 1995). Previously, we reported clinical and biochemical benefits gained by the use of human amniotic epithelial tissue transplantation to patients with some lysosomal storage diseases (Sakuragawa et al. 1992). In addition, using immunocytochemical staining, we found that hAEC expressed markers for both neural and glial cells (Sakuragawa et al. 1996). Recently we reported that hAEC express choline acetyltransferase (ChAT) mRNA and ChAT protein, and actively synthesize and release acetylcholine (Sakuragawa et al. 1997). Moreover, we discovered the presence, synthesis, and release of catecholamines (CA) by hAEC (Elwan and Sakuragawa 1997) and monkey amniotic epithelial cells (Elwan et al. 1998) as indicated by high-performance liquid chromatography-electrochemical detection (HPLC-ECD) studies.

The present study was designed to provide evidence for albumin synthesis and excretion by hAEC. In addition, we 
carried out a transplantation experiment using genetically modified hAEC transplanted through the portal vein of the Scid mouse as a trial for future clinical applications to gene therapy using hAEC as a gene carrier.

\section{Methods}

Preparation of cells

Human amniotic membrane was mechanically peeled from the chorion of a placenta obtained from a woman with an uncomplicated cesarean section and was extensively scraped out to remove the underlying tissues (the spongy and fibroblast layers) to obtain pure epithelial layer with basement membrane. This membrane was used to obtained hAEC, as previously described (Sakuragawa et al. 1995). The obtained hAEC were cultured in $100-\mathrm{mm}$ plastic dishes in RPMI-1640 medium supplemented with $10 \%$ fetal calf serum, streptomycin $100 \mu \mathrm{g} / \mathrm{ml}$, penicillin $100 \mathrm{U} / \mathrm{ml}$, and glutamine $0.3 \mathrm{mg} / \mathrm{ml}$ and incubated under a humidified atmosphere of $5 \% \mathrm{CO}_{2}$ in air at $37^{\circ} \mathrm{C}$.

\section{Immunostaining of cultured hAEC}

Immunostaining, using hAEC grown on coverslips, was performed essentially by the avidin-biotinylated peroxidase complex method, as described before (Sakuragawa et al. 1996). The following primary antibodies were used: rabbit polyclonal antibodies ( $\mathrm{pAb}$ ) to human serum albumin $(1: 2,000$ and $1: 3,000)$ and $\alpha$-fetoprotein $(1: 2,000$; Chemicon International, Temecula CA, USA).

\section{Western blotting}

For Western blotting, cells were homogenized in $500 \mu \mathrm{l}$ of $50 \mathrm{mM}$ Tris- $\mathrm{HCl}$ buffer ( $\mathrm{pH} 7.4$ ) containing $1 \mathrm{mM}$ ethylenediamine tetraacetic acid (EDTA), $1 \mathrm{mM}$ phenylmethylsulfonyl fluoride, and $0.1 \%$ Triton X-100. The homogenate was centrifuged at $13,000 \mathrm{rpm}$ for $60 \mathrm{~min}$. The supernatant was lysed in sodium dodecylsulfate (SDS) buffer and boiled for $5 \mathrm{~min}$, and the sample was subjected to electrophoresis on a $7.5 \%$ polyacrylamide-SDS gel, using a protein mini-apparatus (Bio-Rad, Hercules, CA) at $200 \mathrm{~V}$ for $30 \mathrm{~min}$. The gel was electrically transferred onto a nitrocellulose filter using a Trans-Blot system (Bio-Rad). The filter was blocked and then incubated overnight at $4^{\circ} \mathrm{C}$ with rabbit anti-albumin antibody, followed by three washes with phosphate-buffered saline (PBS) containing $0.05 \%$ Tween 20 (PBS-T). Then the filter was incubated with horseradish peroxidase (HRP)-anti-rabbit IgG for $1 \mathrm{~h}$, followed by several washings with PBS-T, and detection with an (Amersham, Piscataway, NJ). Human liver cells and tissues were used as positive controls for albumin.
Reverse transcription-polymerase chain reaction (RT-PCR)

For the RT-PCR studies, total RNA was extracted by the acid guanidine-phenol-chloroform method. RT was performed with Super Script II RT (GIBCO BRL, Grand Island, NY) with a specific primer for human serum albu$\min \left(5^{\prime}\right.$-CATCAACCTCTGGTCT GACC-3') and $\alpha$-fetoprotein (5'-ATGGGCCAC ATCCAGGACTA-3'). The cDNA product was then amplified for 35 cycles with forward and reverse primers using recombinant Taq DNA polymerase (Takara, Tokyo, Japan) and a thermal cycler. The amplification reaction was performed using a step wise program $\left(94^{\circ} \mathrm{C}, 1 \mathrm{~min} ; 60^{\circ} \mathrm{C}, 1 \mathrm{~min} ; 72^{\circ} \mathrm{C}, 1 \mathrm{~min}\right)$, followed by final extension at $72^{\circ} \mathrm{C}$ for $10 \mathrm{~min}$. The forward primers were 5'-CGTCG AGATGCACACAAGAG-3' for albu$\min$ and 5'-ACTCCAGCATCGATCCC ACT-3' for $\alpha$-fetoprotein. The reverse primers were $5^{\prime}-\mathrm{CAG}$ CAGTCAG CCATTTCACC-3' for albumin and $5^{\prime}$ TGGCTTGGAAAGTTCGGGTC-3' for $\alpha$-fetoprotein. Amplified PCR fragments were subjected to electrophoresis on $2 \%$ agarose gels, stained with ethidium bromide, and visualized by UV illumination.

Detection of albumin in culture medium

The concentration of human serum albumin was determined by a two-antibody immunoassay, as outlined elsewhere (Harlow and Lane 1988). A 96-well plastic plate (Falcon 3915; Becton-Dickinson, Franklin Lakes, NJ, USA) was coated with anti-human albumin goat serum (no. 55109; Cappel, West Chester, PA, USA; $50 \mu \mathrm{l} / \mathrm{well}, 200 \mu \mathrm{g} / \mathrm{ml}$ of antiserum in PBS) at $4{ }^{\circ} \mathrm{C}$ overnight. Control wells were coated with normal goat serum. After each well was washed twice with PBS containing $0.1 \%$ Tween 20, the sample, and standard albumin solution (human serum albumin [01310501; Wako Pure Chemicals, Tokyo, Japan]) dissolved in RPMI-1640 containing 10\% fetal calf serum [FCS]) were added to the wells and allowed to stand for $30 \mathrm{~min}$. The second antibody, HRP-conjugated anti-human albumin sheep IgG (AHP102P; Serotec, Oxford, UK) was dissolved in RPMI-1640 containing 10\% FCS, to absorb cross-reactive antibodies to FCS. After incubation with the second antibody, PBS containing $3 \mathrm{mg} / \mathrm{ml} o$-phenylenediamine (P8412; Sigma, St. Louis, MO, USA) and $0.03 \%$ hydrogen peroxide was added to each well. The detection limit of this system was statistically calculated to be $0.1 \mathrm{ng} / \mathrm{ml}$.

\section{LacZ gene transfection into hAEC}

Recombinant adenovirus containing the $\beta$-galactosidase ( $L a c Z$ ) gene (AxCALacZ) was used (a gift from Dr. I. Saito, University of Tokyo). Cells were exposed to AxCALacZ in a minimal volume at a multiplicity of infection (MOI) of 20. Two days after exposure to the virus, the cells were treated with $0.125 \%$ trypsin, then centrifuged at $1,000 \mathrm{rpm}$ for $10 \mathrm{~min}$. The cells were then resuspended in distilled water at a density of $5 \times 10^{5}$ cells $/ 5 \mu \mathrm{l}$. 
Transplantation of hAEC to Scid mouse through portal vein

Scid mice (CB17; male, 10 to 15-weeks old) were purchased from Japan Clea (Tokyo, Japan). The Scid mouse received anti-asialo GM1 monoclonal antibody (MAb) (Wako Pure Chemicals) intravenously 1 day prior to cell transplantation. Cells were prepared at a concentration of $2.5 \times 10^{5} / \mathrm{ml}$ normal saline. The cell suspension $(250 \mu l)$ was injected through the portal vein (with the animals under ether anaesthesia), using a 29-G needle syringe (Myjecter; Terumo, Tokyo, Japan). One to two weeks after the cell transplantation, the liver was removed and embedded in Tissue-Tek (Sakura Flnechemical, Tokyo, Japan) to obtain cryostat sections. Sections (2- $\mu \mathrm{m}$-thick) were stained with either antibodies for human albumin and $\alpha$-fetoprotein or X-gal for $\beta$-galactosidase. Prior to the immunohistochemical staining, HRP-conjugated anti-human albumin sheep antibody (AHP102P; Serotec) and anti-human $\alpha$-fetoprotein goat antibody (AB635; Chemicon International) were injected to a non-treated Scid mouse, via the tail vein, to absorb cross-reactive antibodies to mouse proteins, and the antibody-containing mouse serum was used for immunostaining. Conjugation of anti-human $\alpha$-fetoprotein with HRP was performed with periodate coupling (Harlow and Lane 1988). Cryosections were incubated with these pre-absorbed sera diluted 1:10 with PBS at room temperature for $1 \mathrm{~h}$, followed by diaminobenzidine staining. $\beta$-galactosidase, a lac $Z$ gene product, was detected by $\mathrm{X}$-gal reaction, using X-gal (no. 027-07854; Wako Pure Chemicals) solution $(4 \mathrm{mg} / \mathrm{ml})$, containing $4 \mathrm{mM}$ potassium ferrocyanide, $4 \mathrm{mM}$ potassium ferricyanide, and $\mathrm{N}, \mathrm{N}$ dimethylformamide. The sections were fixed briefly with neutralized formalin $(10 \%)$ and incubated with X-gal solution at $37^{\circ} \mathrm{C}$ for 1 to $2 \mathrm{~h}$.

All animal experiments were conducted according to the guidelines of the Animal Ethics Committee.

Human polymorphic gene analysis in Scid mouse liver

The human-specific gene was detected by PCR, using primers 5'-GAAACTGGCCTCCAAACACTGCCCGCCG-3' (forward) and 5'-GTCT TGTTGGAGATGCACGT GCCCCTTGC-3' (reverse). Total DNA was extracted from a Scid mouse liver block (approximately $1 \mathrm{~mm}^{3}$ ) by the phenol/chloroform method. The amplification reaction was performed using a step wise program (denaturing, $94^{\circ} \mathrm{C}$, $1.5 \mathrm{~min}$; annealing, $72^{\circ} \mathrm{C}, 2 \mathrm{~min}$; extension, $72^{\circ} \mathrm{C}, 2 \mathrm{~min}$ ) for 40 cycles. Amplified PCR products were subjected to electrophoresis as described above.

\section{Results}

Immunocytochemical staining of cultured hAEC

The cultured cells (Fig. 1) revealed immunoreactivity to the polyclonal antibodies for albumin and $\alpha$-fetoprotein. The

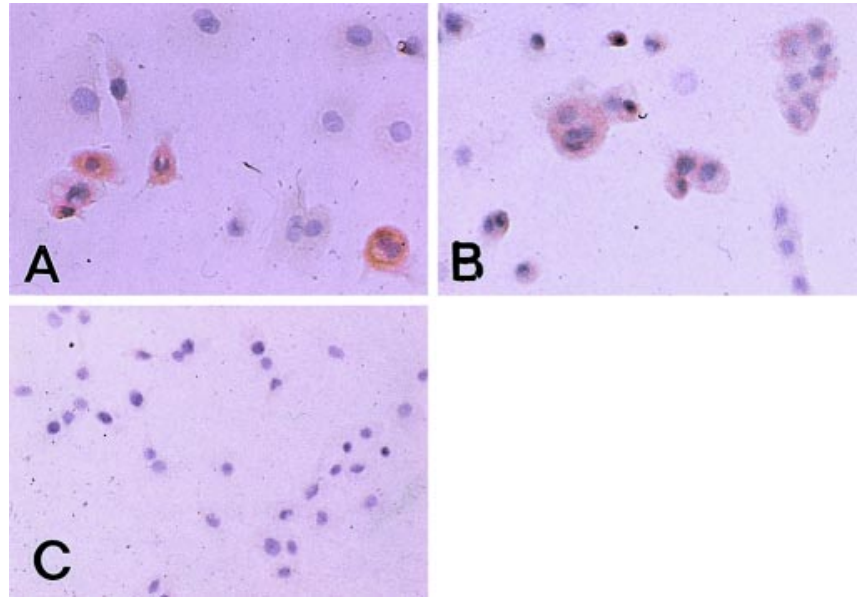

Fig. 1A-C. Immunostaining of human amniotic epithelial cells (hAEC) showed positive immunoreactivity to $\mathbf{A}$ polyclonal antibodies for human albumin and $\mathbf{B} \alpha$-fetoprotein. $\mathbf{C}$ Ig G control $\mathbf{A}, \mathbf{B}, \mathbf{C}, \times 200$

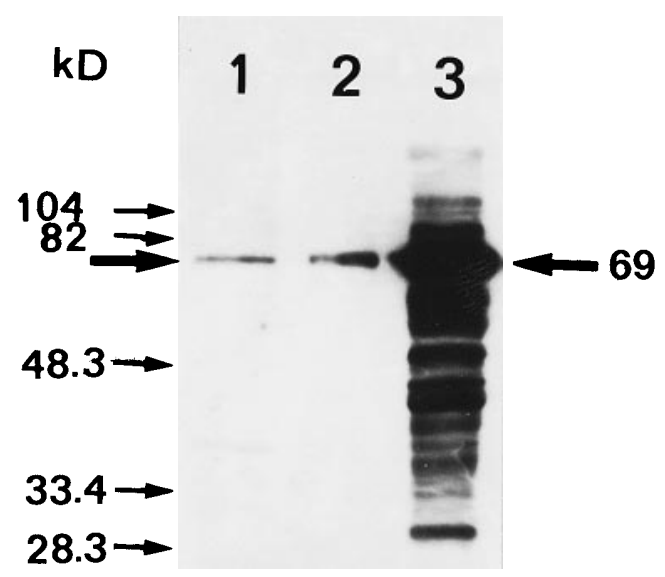

Fig. 2. Western blot analysis of human albumin in hAEC. Lane 1, hAEC; lane 2, human liver cells (ATCC CCL-13 Chang liver); lane 3, human liver tissue, obtained from an autopsy sample from an individual without liver disease. Thick arrows indicate the major band of $69 \mathrm{kDa}$

cultured cells showed a scattered distribution of positively and negatively stained cells, indicating heterogeneous expression of albumin and $\alpha$-fetoprotein in hAEC.

Western blotting and reverse transcription-polymerase chain reaction (RT-PCR)

Western blotting using a polyclonal human albumin antibody showed a major band corresponding to the molecular weight of $69 \mathrm{kDa}$ (Fig. 2). The targeted RT-PCR product, obtained from the tissue and primary cultured cells, suggested the presence of albumin mRNA in the hAEC. $\alpha$ Fetoprotein mRNA was expressed in hAEC, but was not detected in human amniotic epithelial tissues (Fig. 3).

Synthesis of albumin by hAEC

Human albumin concentration in the culture supernatant of hAEC was determined by enzyme-linked immunoassay. A 


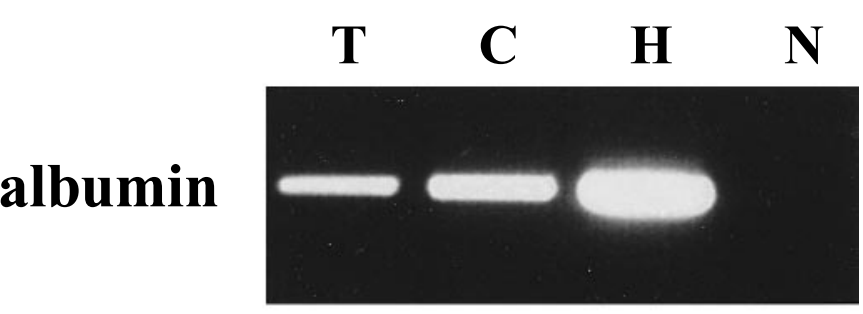

AFP

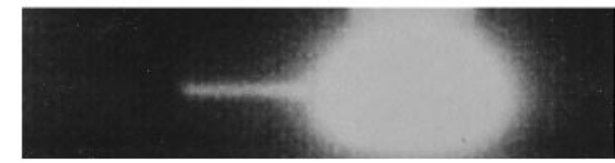

GAPDH

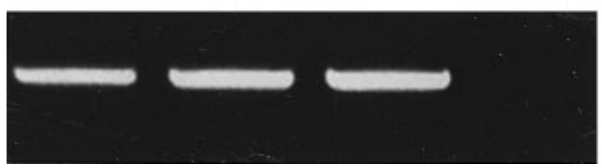

Fig. 3. Expression of human albumin and $\alpha$-fetoprotein $(A F P)$ mRNA in hAEC. Lane 1, Human amniotic epithelial tissue (T); lane 2, hAEC $(C)$; lane 3 , HepG2 cells as a positive control $(H)$; lane 4 , negative control $(N)$. GAPDH

significant level of human albumin was detectable from day 5 after the first passage of the cells. The concentration appeared to increase with culture time with the five samples obtained from five independent donors. Normally, hAEC grow under primary culture conditions and passages are performed once or twice a week. Albumin synthesis, however, was unlikely to start during the growing stage. Actually, albumin was detectable only from 5 days after the passage, ie, albumin was secreted after hAEC were in the fully confluent state. With the enzyme-linked immunoassay, albumin was detected in the cell incubation medium after 9 days of cultivation, with the medium containing $2.83 \pm$ $2.05 \mathrm{ng} / \mathrm{ml}$.

Transplantation of genetically modified hAEC into liver of Scid mouse

Immunostaining of Scid mouse liver 2 weeks after the injection of hAEC through the portal vein showed immunoreactive cells to antibodies for anti-human albumin (Fig. 4A) and anti-human $\alpha$-fetoprotein (Fig. 4B). X-gal staining of liver 1 week after the transplantation of hAEC transfected with the $L a c Z$ gene revealed several blue cells in the parenchyma of liver (Fig. 4C,D), indicating that the transplanted cells had been integrated into the hepatic parenchyma within a few days.

Human polymorphic gene analysis in Scid mouse liver after implantation of hAEC

The human gene-specific tandem repeat, D1S58 defined by the DNA probe for pMCT118, was detected after the hAEC transplantation (Fig. 5). Identical bands were amplified with liver transplanted with hAEC from the same do-

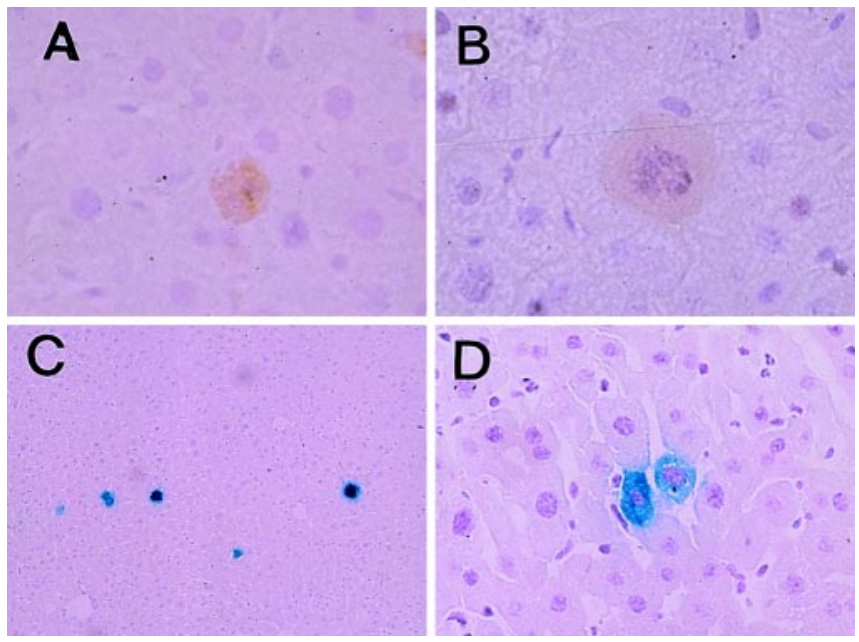

Fig. 4A-D. Immunostaining of Scid mouse liver 1 to 2 weeks after the transplantation of genetically modified cells via the portal vein showed cells with positive reactivion to $\mathbf{A}$ human serum albumin and $\mathbf{B} \alpha$ fetoprotein. C, D X-gal staining of Scid mouse liver 1 week after the transplantation of genetically modified cells via the portal vein showed a few blue cells in the parenchyma of liver. $\mathbf{A}, \mathbf{B} \times 400 ; \mathbf{C} \times 100 ; \mathbf{D} \times 400$

nor, as the gene is inherited from both parental genomes and is polymorphic (Kasai et al. 1990). These Scid mouse livers obviously contained this human-specific gene until day 7 after the cell transplantation, whereas no PCR product was detected with DNA from normal Scid mouse under the present conditions.

\section{Discussion}

In the present study, immunostaining of cultured hAEC demonstrated the presence of immunoreactivities to albu$\min$ and $\alpha$-fetoprotein. In addition to immunocytochemical staining, the present study utilized different techniques to demonstrate that hAEC possess native albumin synthesis activity. Western blotting showed the presence of albumin, while RT-PCR analysis revealed the expression of albumin mRNA by hAEC. Moreover, the enzyme-linked immunoassay provided further evidence for the presence of albumin and showed the capability of hAEC to synthesize and secrete albumin. Regarding the site of albumin expression, albumin can be visualized within the cytoplasm of liver cells by anti-albumin antibodies carrying a fluorescent or peroxidase label. Albumin mRNA was readily observed in liver, but no transcripts were found in other organs, such as kidney, brain, heart, lung, or intestine (Peters 1992). We found evidence of the synthesis and secretion of albumin in hAEC, although it was a small amount compared with findings in rat hepatocytes cultured in serum-free medium containing glucagon, insulin, and dexamethasone (Dahn et al. 1993). It is interesting to note that amniotic fluid contains about $2 \mathrm{~g} / \mathrm{l}$ of albumin (Bala et al. 1987). It is well known that the placenta is a highly selective organ in its transport of plasma proteins, including albumin. Labeled albumin 
Fig. 5. Polymerase chain reaction (PCR) analysis of human polymorphic gene in Scid mouse liver. Livers were excised on the day indicated and total DNA was extracted. The human genespecific tandem repeat, DIS58 defined by the DNA probe for pMCT 118. Lane $A$, Size marker; lane $B$, hAEC; lane $C$, normal Scid mouse liver; lanes $D-I$, Scid mouse liver transplanted with hAEC, 1 h $(D), 1$ day $(E), 2$ days $(F), 3$ days $(G), 4$ days $(H)$, and 7 days $(I)$ after the cell transplantation

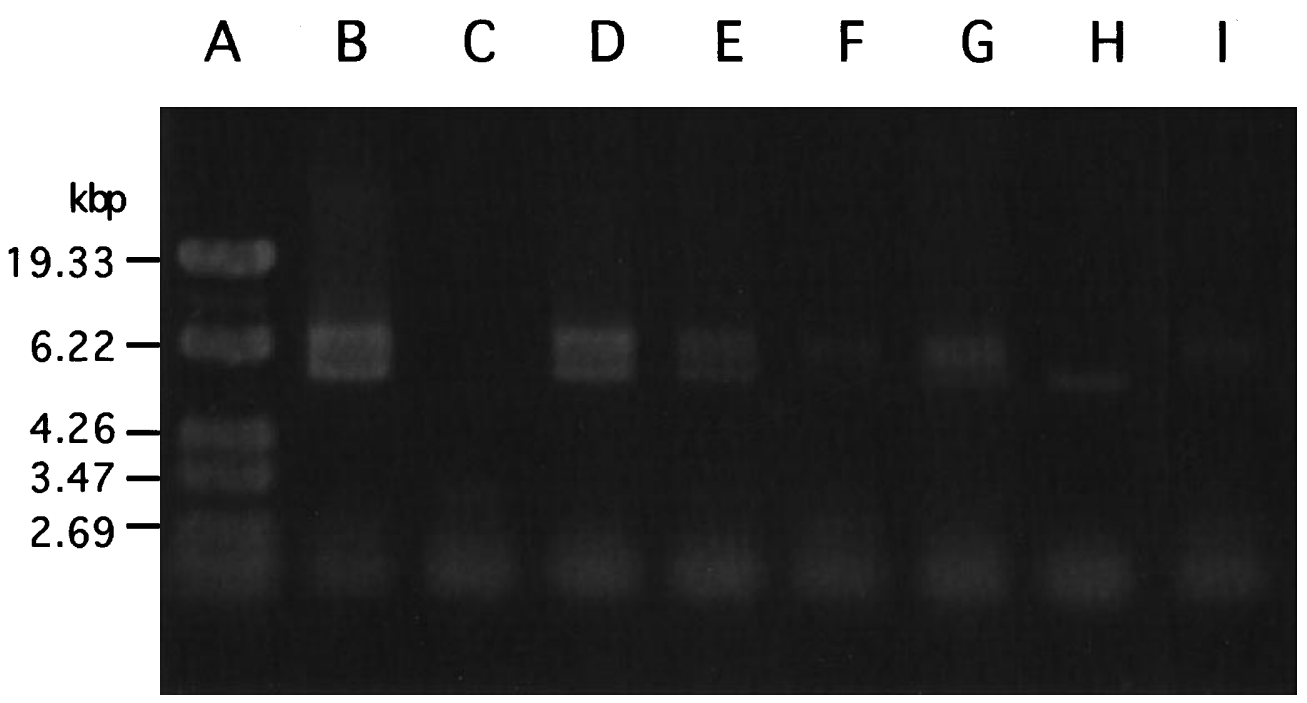

injected into a mother appears, in the fetus after 25 days, with no more than $5 \%$ of the maternal-specific activity (Gitlin et al. 1964). Further studies are now underway to elucidate whether amniotic epithelial cells may be a source of albumin in amniotic fluid.

Hepatocyte transplantation has been proposed for "gene therapy" for various types of inherited diseases expressed in the liver, and as treatment for acute liver failure of various causes. Indeed, hepatocyte transplantation has already been employed in a number of genetic liver diseases, including ornithine transcarbamylase deficiency (Reyers et al. 1996), familial hypercholesterolemia caused by a deficiency of low-density lipoprotein (LDL) receptors (Raper et al. 1996), and Crigler-Najjar syndrome type I (Fox et al. 1998). Experimentally, hepatocyte transplantation was successful in the Gunn rat and the Nagase analbuminemia rat. Xenogeneic hepatocellular transplantation provided functional LDL receptors that lowered serum cholesterol in the Watanabe heritable hyperlipidemic (WHHL) rabbit by $30 \%-60 \%$ for at least 100 days (Gunsalus et al. 1997). Acute liver failure is usually life-threatening, because of severe metabolic disturbance associated with multiple organ failure, hepatic coma, and encephalopathy. Because of the shortage of donor organs for orthotopic liver transplantation, several bridging techniques have been proposed to sustain patients until transplantation, including the temporary use of a xenogeneic organ (Starzl et al. 1993) and the use of a bioartificial liver (Strom et al. 1997). Lake (1998) suggested that the use of hepatocyte transplantation as treatment for a number of genetic and nongenetic diseases should be explored continuously, because there is a critical shortage of donor livers for patients with liver failure.

An attempt to use syngeneic fibroblasts for a transgene carrier was reported recently with the Gunn rat model; these genetically modified cells were shown to be effective in reducing unconjugated bilirubin level after transplantation into the peritoneal cavity (Seppen et al. 1997). However, Seppen et al. (1997) found that the fibroblasts formed a tumor 6 weeks after transplantation, suggesting that heterotopic localization of the physiological function may be undesirable. In this sense, hAEC will be more suitable as a transgene carrier to the liver than fibroblasts or other nonhepatic cells, as hAEC expressed mRNA of albumin and $\alpha$ fetoprotein in addition to showing synthesis and excretion of albumin.

Current research strategies to develop hepatocyte transplantation for acute liver failure of any cause and to develop gene therapy for inherited metabolic disorders expressed in the liver are directed towards finding suitable sources of cells for grafting. Stem cells of human origin (if available), which can differentiate into hepatocytes when transplanted into the liver, would be ideal. From the present findings that hAEC possess native albumin synthesis capacity and express liver lineage markers and that these cells are immunologically naïve, we believe that these criteria may qualify hAEC to be considered as a possible candidate cell type for hepatocyte transplantation in acute liver diseases. Although transplanted cells were reported to survive and function in vivo for almost 1 month (Sakuragawa et al. 1992), we were able to plot the gene markers in vivo 2 weeks after transplantation. Genetically modified HAE cells are being used for experimental gene therapy in the Gunn rat and the WHHL rabbit, in studies which are now underway. In addition to hAEC being of human origin, non-tumorous, easily available, and in continuous unlimited supply, the use of hAEC does not seem to involve ethical problems, which do occur with orthotopic liver transplantation or xenogeneic transplantation.

Acknowledgments We thank Keiko Ohsugi, Yukiko Inanaga, and MA Elwan for technical assistance and preparing the manuscript.

This work was supported in part by Health Sciences Research Grants for Research on Brain Science and Research on Advanced Medical Technology and by a Science Grant (8A-9) for Nervous and Mental Disorders from the Ministry of Health and Welfare of Japan.

\section{References}

Bala S, Seth S, Seth PK (1987) Albumin concentration in human amniotic fluid from normal pregnancies. Acta Paediatr Hung 28:187-192 
Dahn MS, Hsu CJ, Lange MP, Kimball SP, Jefferson LS (1993) Factors affecting secretory protein production in primary cultures of rat hepatocytes. Proc Soc Exp Biol Med 203:38-44

Demetrious AA, Whitting JF, Feldman D, Levenson SM, Chowdhury NR, Moscioni AD, Kranm M, Chowdhury JR (1986) Replacement of liver function in rats by transplantation of microcarrier-attached hepatocytes. Science 233:1190-1192

Elwan MA, Sakuragawa N (1997) Evidence for synthesis and release of catecholamines by human amniotic epithelial cells. Neuroreport 8:3435-3438

Elwan MA, Thangavel R, Ono F, Sakuragawa N (1998) Synthesis and release of catecholamines by cultured monkey amniotic epithelial cells. J Neurosci Res 53:107-113

Fox IJ, Chowdhury JR, Kaufman SS, Goertzen TC, Chowdhury NR, Warkentin PI, Dorko K, Sauter BV, Strom SC (1998) Treatment of the Crigler-Najjar syndrome type I with hepatocyte transplantation. New Engl J Med 338:1422-1426

Gitlin D, Kumate J, Urrusti J, Morales C (1964) The selectivity of the human placenta in the transfer of plasma proteins from mother to fetus. J Clin Invest 43:1938-1951

Grisham JW, Thorgeirsson SS (1997) Liver stem cells. In: Potten CS (ed) Stem cells. Academic Press, London, pp 233-282

Gunsalus JR, Brady DA, Coulter SM, GrayBM, Edge ASB (1997) Reduction of serum cholesterol in Watanabe rabbits by xenogeneic hepatocellular transplantation. Nature Medicine 3:48-53

Gupta S, Aragona RP, Vemuru E, Bhargava KK, Burk RD, Chowdhury JR (1991) Permanent engraftment and function of hepatocytes delivered to the liver: implications for gene therapy and liver repopulation. Hepatology 14:144-149

Harlow E, Lane D (1988) Two antibody-immunoassay. In: Harlow E, Lane D (eds) Antibodies, a laboratory manual. New York: Cold Spring Harbor Laboratory Press

Kasai K, Nakamura Y, White R (1990) Amplification of a variable number of tandem repeat (VNTR) locus (pMCT118) by the polymerase chain reaction (PCR) and its application to forensic science. J Forensic Sci 35:1196-1200

Lake JR (1998) Hepatocyte transplantation. New Engl J Med 338:1463-1464

Peters T Jr (1992) Metabolism: albumin in the body. In: Peters T Jr (ed) All about albumin. Biochemistry, genetics, and medical applications.
Academic Press, San Diego, pp 188-250

Raper SE, Grossman M, Rader DJ, Thoene JG, Clark III BJ, Kolansky DM, Muller DWM, Wilson JM (1996) Safety and feasibility of liver directed ex vivo gene therapy for homogeneous familial hypercholesterolemia. Ann Surg 223:116-126

Reyers J, Rubinstein EW, Mieles L, Strom SC, Towbin RB, Tarucco M, Charron M, Barranger JA (1996) The use of cultured hepatocyte infusion via the portal vein for the treatment of ornithine transcarbamylase deficiency by transplantation of enzymatically competent ABO/Rh-matched cells. Hepatology 24:Suppl 308A

Sakuragawa N, Yoshikawa H, Sasaki M (1992) Amniotic tissue transplantation: clinical and biochemical evaluation for some lysosomal storage diseases. Brain Dev 14:7-14

Sakuragawa N, Tohyama J, Yamamoto H (1995) Immunostaining of human amniotic epithelial cells: possible use as a transgene carrier in gene therapy of inborn errors of metabolism. Cell Transplant 4:343346

Sakuragawa N, Thangavel R, Mizuguchi M, Hirasawa M, Kamo I (1996) Expression of markers for both neuronal and glial cells in human amniotic epithelial cells. Neurosci Lett 209:9-12

Sakuragawa N, Misawa H, Ohsugi K, Kakishita K, Ishii T, Thangavel R, Tohyama J, Elwan MA, Yokoyama Y, Okuda O, Arai H, Ogino I, Sato K (1997) Evidence for active acetylcholine metabolism in human amniotic epithelial cells: applicable to intracerebral allografting for neurologic disease. Neurosci Lett 232:53-56

Seppen J, Tada K, Ottenhoff R, Sengupta K, Chowdhury NR, Chowdhury JR, Bosma RO (1997) Transplantation of Gunn rats with autologous fibroblasts expressing bilirubin UDP-glucuronosyltransferase: correction of genetic deficiency and tumor formation. Hum Gene Ther 8:27-36

Sigal SH, Brill S, Fiorino AS, Reid LM (1992) The liver as a stem cell and lineage system. Am J Physiol 263:G139-G148

Starzl TE, Fung J, Tzakis A, Todo S, Demetris AJ, Marino LR, Doyle H, Zeevi A, Warty V, Michaele M, Kusne S, Rudert WA, Trucco M (1993) Baboon-to-human liver transplantation. Lancet 341:6571

Strom SC, Fisher RA, Thompson MT, Sanyal AJ, Cole PE, Ham JM, Posner MP (1997) Hepatocyte transplantation as a bridge to orthotopic liver transplantation in terminal liver failure. Transplant 63:559-569 